\title{
UMA EXPERIÊNCIA PEDAGÓGICA NO ENSINO MÉDIO INTEGRADO: PESQUISANDO OS AGENTES COMUNITÁRIOS DE SAÚDE
}

\section{A TEACHING EXPERIENCE IN THE INTEGRATED MIDDLE EDUCATION: RESEARCHING THE COMMUNITY HEALTH AGENTS}

\author{
Ialê Falleiros Braga ${ }^{1}$ \\ Marcia Cavalcanti Raposo Lopes ${ }^{2}$
}

\begin{abstract}
Resumo Este texto tem como proposta relatar uma experiência pedagógica com alunos do ensino técnico na Escola Politécnica de Saúde Joaquim Venâncio, Fiocruz (EPSJV/Fiocruz). Essa experiência, que teve duração de um semestre, enfocou a temática "Agentes comunitários de saúde (ACS) política, formação e trabalho", com o objetivo de proporcionar aos alunos uma introdução à pesquisa, seguindo a proposta de iniciação à educação politécnica em saúde da EPSJV. Alunos e preceptoras entraram em contato com as políticas voltadas à formação e ao trabalho dos ACS e conversaram com pesquisadores da área e ACS. O trabalho resultou na elaboração de um vídeo-documentário e na produção coletiva deste relato. $\mathrm{O}$ trabalho introdutório de pesquisa em questão retirou alunos e preceptoras dos lugares de 'mestres sábios' e 'aprendizes ignorantes', dando-lhes a oportunidade de romper com o modelo bancário de educação e levando-os a olhar o processo de aprendizagem e o objeto de estudo numa perspectiva crítica.
\end{abstract}

Palavras-chave pesquisa; educação; trabalho; saúde; agentes comunitários.

\begin{abstract}
This article reports on a teaching experience carried out with technical education students at Fiocruz's Joaquim Venâncio Polytechnic School of Health (EPSJV/Fiocruz). This experience, which lasted one semester, focused on "Community Health Agents (CHA) - policy, qualification, and work," and aimed to provide the students with an introduction to research following the proposal of initiation to EPSJV's polytechnic education in health. Students and educators analyzed the CHA qualification and work policies and had a chance to discuss the issue with researchers involved in this area and with CHAs. The outcome of the work was the production of a documentary video and the collective preparation of this report. This introductory work in research repositioned students and educators away from the standard condition of "wise master" and "ignorant apprentice," and gave them the chance to break away from the banking model of education and to gain an critical view of the learning process and of the study's object.
\end{abstract}

Keywords research; education; work; health; community agents. 
Travamos nossa luta por responsabilidade contra um ser mascarado. A máscara do adulto chama-se 'experiência'. Ela é inexpressiva, impenetrável, sempre a mesma. Esse adulto já vivenciou tudo: juventude, ideais, esperança (...). Foi tudo ilusão. - Ficamos, com freqüência, intimidados ou amargurados. Talvez ele tenha razão. O que podemos objetar-lhe? Nós ainda não experimentamos nada. Mas vamos tentar agora levantar essa máscara.

(Benjamin, 2002, p. 21)

\section{Começo de conversa}

Início do ano letivo de 2007. Tarde abafada de terça-feira. Os corredores da escola com pessoas vestidas de 'pais-de-santo', 'anjos' e 'borboletas', segurando sacos de confete e espalhando purpurina para todos os lados. Em meio a essa agitação se deu a primeira reunião de iniciação à pesquisa do grupo cujo relato vamos apresentar.

A escola de que falamos é um centro de pesquisa e ensino, um lugar cheio de gente séria que estuda a relação trabalho-educação em saúde e desenvolve trabalhos que informam as práticas pedagógicas, bem como as políticas nesta área. Estamos falando da Escola Politécnica de Saúde Joaquim Venâncio, da Fundação Oswaldo Cruz (EPSJV/Fiocruz). Essa gente séria é ao mesmo tempo animadíssima, adora dançar e fazer bagunça em ocasiões festivas.

Era esse, pois, o clima do dia daquela reunião. Estava marcado para o final da tarde de fevereiro o baile de carnaval, e um pequeno grupo de oito alunos, junto a duas preceptoras, começava a tomar contato com a proposta do Trabalho de Integração (TI) feita pela coordenação do módulo introdutório, oferecido pela escola aos alunos ingressantes nas diversas habilitações técnicas 3 , denominado Iniciação à Educação Politécnica em Saúde (IEP): um estudo introdutório sobre os agentes comunitários de saúde (ACS). $\mathrm{O}$ enfoque sobre esses profissionais deveria abarcar a política, a formação e o trabalho.

O grupo de alunos sentados em círculo, recém-ingressante na EPSJV, havia sorteado o tema em meio a outros (mais interessantes?), seguindo a proposta, ainda inédita, de desenvolver alguns fundamentos sobre metodologia de pesquisa no início da formação técnica de nível médio.

Segundo duas dessas alunas: 
Mal nos conhecíamos, e as poucas amizades que fizemos foram separadas nas turmas A, B e C. Dentro das turmas do IEP, tivemos que nos dividir em grupos para o TI. Durante a formação dos grupos, os futuros integrantes do nosso grupo não se moveram para formá-lo. Enquanto isso, os outros grupos iam sendo formados no meio de uma enorme empolgação. Terminada essa empolgação, sobraram oito pessoas sem grupo. Quem eram? Éramos nós, e, quase que forçados, tivemos que nos juntar. (...) Ficamos indignados com o sorteio e durante horas tentamos trocar com os outros grupos de tema. Felizmente, ninguém aceitou (Mariana).

Ficamos um pouco chateados com nossa 'sorte' (Sheila).

\section{Nossa rotina de aprendizado e criação}

O que é ensinar e aprender? O que devemos aprender, por que e para quê? Como sabemos se aprendemos o suficiente ou não? Quem define o que é suficiente? Estas questões, entre outras que nos acometiam, vinham e voltavam, continuamente, nas salas de aula, tanto na cabeça dos professores, ao pensarem em como fazer o seu trabalho, como na mente dos alunos, ao buscarem sentidos para sua freqüência aos, quase sempre aborrecidos, cursos escolares 4 .

Quando falamos de educação profissional, ou de formação técnica, estas perguntas se tornam ainda mais pertinentes, já que colocam em questão a organização social do trabalho em nossa sociedade 5 .

Assim, a experiência de acompanhar os alunos ingressantes no ensino médio no Trabalho de Integração (TI) na EPSJV nos aponta alguns aspectos interessantes para essa discussão. De acordo com a proposta do TI, as preceptoras deviam aproximar os alunos de um processo de pesquisa a partir de um tema determinado - no nosso caso, os agentes comunitários de saúde (ACS) -, buscando interligar as diversas discussões propostas aos alunos no módulo inicial do curso técnico oferecido pela escola, o IEP.

Enorme desafio que exigiu de nós, preceptoras e alunos, construir um curso cujo objetivo não era simplesmente, como acontece em geral, apropriar-se de um conteúdo determinado.

O desconhecimento sobre o assunto pesava sobre a proposta de trabalho.

Havia outros temas mais instigantes num primeiro olhar, como 'a despoluição da Baía de Guanabara' ou 'transplante de órgãos'. As preceptoras sentadas naquele círculo também eram iniciantes na temática dos agentes comunitários de saúde e deixaram claro que iriam contar com a ajuda dos colegas pesquisadores da escola, que conheciam o assunto, para 
desenvolver a proposta. Se para elas o assunto era novo e inexplorado, para os alunos era uma verdadeira incógnita, como relata um deles:

Após o sorteio dos temas, e de conhecer os meus companheiros de grupo, começamos a pensar no que seria um ACS. Pensamos que fossem os agentes combatentes da dengue, mas, após a primeira reunião, vimos que era algo, ao mesmo tempo, diferente e parecido (Marco Antônio).

Além disso, o entrosamento também era um problema para o grupo. Seis, dos oito alunos que o compunham, não faziam o ensino médio na escola e só a freqüentavam no curso técnico oferecido no período da tarde... e nossos encontros eram quinzenais. Por outro lado, apesar do desânimo diante do sorteio e da resistência em pesquisar uma categoria profissional desconhecida por quase todos, o grupo, que contava com maioria já concluinte do ensino médio, enfrentou com maturidade a proposta desde o primeiro dia.

Muitas questões se colocavam para as preceptoras. Como desenvolver o tema de modo a atingir o objetivo proposto, escapando do modelo das aulas tradicionais, construindo um espaço de questionamentos, como deve ser um início de pesquisa, e possibilitando o desenvolvimento da autonomia dos alunos? Partindo do pressuposto de que só se pode perguntar sobre conteúdos minimamente conhecidos, as preceptoras julgaram que discutir sobre o tema com pesquisadores da escola poderia ser - senão o ideal (já que ficaríamos um pouco com o modelo de aulas) - um começo interessante.

Assim, nossas reuniões iniciais foram preparadas pelas preceptoras de forma a apresentar os ACS a partir de relatos de alguns profissionais da área e de pessoas ligadas à formação e à política de regulamentação dessa categoria profissional6. Márcia Valéria Morosini ${ }^{7}$ foi convidada para conversar conosco e expor a situação atual do trabalho e da formação dos ACS. Ela nos contou que o Programa de Agentes Comunitários de Saúde (Pacs), surgido em 1992, teve origem no Movimento Popular de Saúde (Mops) e ganhou amplitude pelo trabalho dos primeiros agentes, voltado às questões materno-infantis, em especial ao incentivo ao pré-natal entre as gestantes e ao combate à mortalidade por desidratação infantil, graças à difusão do uso do soro caseiro entre as famílias das regiões mais empobrecidas do Brasil. Nesse histórico do trabalho dos ACS, o Programa Saúde da Família (PSF), criado em 19948, tem um capítulo fundamental segundo Márcia Valéria. A partir de então, os municípios que o adotaram passaram a incorporar esses profissionais à equipe de saúde da família, juntamente com o médico, o enfermeiro e outros profissionais de saúde. Mas todos nós queríamos saber: o que é específico do trabalho de um ACS? Contou também que as diretrizes para o trabalho do ACS foram fixadas pelo decreto $\mathrm{n}^{\circ} 3.189 / 1999$, e, 
após sua apresentação, um dos pontos que geraram mais polêmica entre os alunos foi a exigência definida por este decreto desse profissional não poder deixar de morar na comunidade onde atua.

A pesquisadora apresentou um quadro relativo às diferentes formas de contratação dos ACS (terceirizados, bolsistas etc.) ao longo desses vinte anos de atuação e ressaltou a importância da lei $n^{\circ} 11.350 / 2006$ para a regulamentação de seu trabalho, tornando-os servidores públicos vinculados diretamente aos poderes municipal, estadual ou federal e contratados mediante concurso público.

No que se refere à formação desses profissionais, informou que essa lei também define que deve haver uma formação específica além do ensino fundamental completo, e que foram elaboradas diretrizes curriculares para a formação dessa categoria profissional. Um dos alunos assim se expressou sobre os ACS: "O que mais nos impressionou foi o fato de um profissional tão importante ter tão pouco reconhecimento e nós o conhecermos tão pouco..." (Ricardo).

Deste bate-papo cheio de informações passamos a um pequeno levantamento bibliográfico na Biblioteca Emília Bustamante, da EPSJV, e na Biblioteca Virtual de Saúde (BVS). A idéia era explorar o espaço da biblioteca da escola, permitindo que os alunos conhecessem o acervo e as potencialidades de pesquisa.

As preceptoras pediram aos alunos que selecionassem um texto relativo ao tema em estudo. Os textos escolhidos foram trabalhados no encontro seguinte. Um deles era uma proposta de terceirização do trabalho dos ACS por Organizações da Sociedade Civil de Interesse Público (Oscip), publicado pelo Ministério da Saúde no final do governo FHC (Brasil, 2002). Os alunos, que já vinham iniciando o debate sobre a precarização do trabalho, característica do contexto neoliberal no Brasil, puderam aprofundá-lo a partir desse documento. Outro texto selecionado era uma página, recentemente publicada no site do Ministério da Saúde na internet, onde havia algumas perguntas e respostas sobre o trabalho e a formação dos ACS. Partimos dessas perguntas para mapear o que já conhecíamos sobre o assunto e preparar algumas perguntas para fazer a Cátia Corrêa Guimarães ${ }^{9}$, convidada para uma entrevista com os alunos 10 . A conversa centrou-se na questão da formação técnica dos ACS. Uma das perguntas elaboradas pelos alunos foi sobre o papel da EPSJV nesta formação. Ela afirmou que as escolas técnicas do Sistema Único de Saúde (Etsus) são responsáveis pela formação do primeiro módulo de formação desses profissionais e que a EPSJV organizou um material voltado aos professores dos cursos de formação de ACS (Morosini, 2007) e vem se preparando para assumir parte desta formação. Tivemos ainda um encontro com Anamaria Corbol1. Esse encontro se construiu a partir das várias dúvidas que foram surgindo com as 
discussões anteriores. Nele, os alunos puderam dialogar com a experiência trazida por ela com as equipes de Saúde da Família da ilha de Paquetá, no Rio de Janeiro. Entre tantas narrativas que mobilizaram muito o grupo de alunos, destaca-se uma sobre como uma dessas equipes conseguiu bons resultados no cuidado de uma pessoa que sofria de psicose.

Nossos encontros, aos poucos, tornaram-se mais descontraídos e interessantes, despertando alguma curiosidade entre nós. Estávamos mais entrosados e mais à vontade e, a esta altura dos acontecimentos, o tema de nosso estudo começava a se tornar mais próximo. Era abril, e Tereza Ramos (2007), presidente da Confederação Nacional dos Agentes Comunitários de Saúde, e ACS de Recife, foi convidada para dar a aula inaugural da EPSJV12. Os ACS ganhavam relevo nas discussões no espaço escolar como um todo, o que facilitava a função das preceptoras de despertar o interesse dos alunos. Alguns alunos relatam:

(...) nós começamos a entender um pouco desse trabalho que os agentes comunitários realizam, mas mesmo assim não ficamos muito animados (...) (Thaciana).

Os primeiros encontros foram muito tímidos, sem o nosso interesse pelo tema e devido a isto foram pouco produtivos. Já os demais encontros foram repletos de debates, dúvidas e brincadeiras. Ao longo dos encontros fomos nos tornando amigos e os quinzenais foram se tornando mais agradáveis (Mariana).

Como a proposta do TI incluía trabalhos de campo e os outros grupos vinham fazendo 'excursões', visitando serviços fora do campus da Fiocruz, os alunos cobravam das preceptoras a possibilidade de também saírem do espaço escolar e pediam para conhecer mais de perto o trabalho dos ACS. Eles estavam frustrados, pois as saídas a campo - previstas para o TI foram, sucessivamente, adiadas pela dificuldade de agendamento. Na realidade, havíamos feito uma visita ao Centro de Saúde da Escola Nacional de Saúde Pública Sergio Arouca, da Fundação Oswaldo Cruz (Ensp/Fiocruz), mas não conseguimos conversar com a pessoa responsável pelas equipes de saúde da família. As preceptoras não queriam se precipitar em levar o grupo para um acompanhamento de visitas domiciliares em regiões de alto índice de violência.

Nesse sentido, um aluno avalia que

(...) o trabalho poderia ser mais dinâmico, com mais visitas a campo, mas na sala de aula o pessoal da RET-SUS e a Márcia Valéria esclareceram muito bem a maioria das nossas dúvidas, como a distribuição das escolas [Etsus] no Brasil e também como eram feitas as aulas em lugares de difícil acesso, o objetivo dos ACS e sua situação política (Diego). 
Chegávamos ao meio do semestre e a preocupação com a construção de um trabalho para apresentar no final das atividades do TI começou a aparecer. Havia uma proposta inicial de chamar alguns ACS e pesquisadores para um debate e filmar o encontro. Ao longo do trabalho, entretanto, mudamos de idéia. As preceptoras buscavam uma maneira de compensar o fato de sermos o único grupo que não havia saído a campo. Elas propuseram que fosse realizado um vídeo-documentário sobre os ACS. Como os alunos se mostraram entusiasmados, elas lhes apresentaram alguns vídeo-documentários ${ }^{13}$ e convidaram um profissional e uma estagiária do Núcleo de Tecnologias Educacionais em Saúde (Nuted), da EPSJV, Gregório Galvão Albuquerque e Chaiana Furtado, bem como a professora de artes, também da escola, Verônica de Almeida Soares, para discutir as diferentes linguagens utilizadas e ajudar na reflexão coletiva sobre as possibilidades de realização da proposta e os passos para que se concretizasse.

Este dia se tornou um marco em nosso processo. Os alunos se envolveram totalmente com a idéia do vídeo e saíram da reunião assumindo o compromisso de realizá-lo, mesmo com o curto tempo disponível entre a preparação do roteiro, as filmagens, a edição e finalização e as limitações técnicas - ter que aprender a operar a câmera e o equipamento de som, além de aprender a editar.

A Márcia e a Ialê nos deram a sugestão de fazer um vídeo; adoramos a idéia e logo concordamos. No encontro seguinte, estivemos com o pessoal do Núcleo de Tecnologia da escola; não foi muito agradável, pois eles nos passaram a dura realidade, falaram que o tempo era curto e que filmar não era tão fácil assim como parecia. Nos deparamos com uma enorme dúvida que era a de fazer ou não fazer o vídeo. Resolvemos nos reunir e decidir o que seria feito. Saímos desta reunião com a idéia fixa de que mesmo com todas as dificuldades nós iríamos fazer este vídeo (Mariana).

O Nuted passou a ser o lugar de referência para o nosso grupo. Os alunos assumiram com total autonomia o trabalho de confecção do roteiro e captura das primeiras imagens. Visitaram novamente o Centro de Saúde da Ensp, conheceram três ACS num só dia, entrevistaram pessoas diversas. As preceptoras, finalmente, conseguiram fazer alguns contatos que nos levaram à ACS Patrícia Evangelista da Silva, e à 'atriz' principal do vídeo, a ACS Janete da Silva14. Esta última nos concedeu uma longa entrevista na qual pudemos aprender sobre sua rotina e dificuldades de trabalho, assim como sobre o que ele tem de bom e nos autorizou a filmá-la.

Nesta etapa do processo, os alunos tomaram a frente das atividades e, entre brigas e contendas, começaram a editar o vídeo contando com auxílio das preceptoras apenas para sistematização e intermediação das diferenças. 
Eles se apropriaram das diferentes tecnologias que a confecção do vídeo exigia e mergulharam nas discussões que deviam ser incorporadas como conteúdo do filme - a política, o trabalho, a formação dos ACS.

Sobre este percurso uma aluna comenta:

As semanas foram se passando e o nosso trabalho aumentando, passávamos a tarde inteira, e às vezes dias inteiros, no Nuted. Apesar de toda a nossa força de vontade, éramos leigos na frente daqueles computadores de alta tecnologia. Fomos aprendendo aos poucos e, com a ajuda do Gregório, fomos editando nosso vídeo (Mariana).

Nossas reuniões tornaram-se cada vez mais animadas, implicando novas descobertas e interesses. A possibilidade de uso da nova linguagem exercia um encantamento sobre os alunos - agora muito mais participativos. O lugar das preceptoras também foi deslocado, não mais representantes de um saber a ser apreendido, mas co-construtoras de um processo coletivo, no qual, em muitos momentos, os alunos dominavam mais do que elas as técnicas necessárias para o seu bom desenvolvimento. As diferenças também apareciam com mais intensidade, o que, se por um lado tornou o processo mais difícil, por outro nos aproximou mais nas negociações e construções de consensos. Este é o balanço deste momento, realizado por uma aluna:

O processo de elaboração do vídeo foi difícil, porque nem sempre todos concordavam com o andamento do roteiro que era proposto por alguns. Depois de muita conversa e até alguns desentendimentos, o grupo conseguiu chegar a um objetivo comum: mostrar como um ACS trabalha e vive nestas comunidades e como é passar por situações de tanta desigualdade todos os dias (Thaciana).

Durante este processo, também tivemos oportunidade de fazer - finalmente! - uma visita de campo.

Fomos ao Posto de Atendimento Médico (PAM) Oswaldo Cruz, no centro do Rio de Janeiro, entrevistar uma turma de ACS recém-formada no primeiro módulo do curso técnico. Pudemos, ali, conversar com esses trabalhadores sobre sua formação e sobre seu trabalho, enriquecendo nossas discussões construídas a partir dos estudos realizados e da entrevista com a Janete. Tornavam-se mais freqüentes algumas reflexões como a relatada por esta aluna:

(...) apesar da importância dos serviços que realizam, estes trabalhadores são desvalorizados. (...) É importante ressaltar que [eles] não são a solução para o Sistema de Saúde, e sim ajudam a complementar e tornar eficiente o [seu] funcionamento (...) (Sheila). 
Início de julho. Chegava a hora de terminar o TI, era preciso finalizar o vídeo e preparar uma apresentação. Nossos encontros haviam acabado e só nos restavam alguns dias para o seminário de apresentação. Neste ponto, os alunos, com a ajuda do pessoal do Nuted, assumiram completamente o trabalho - o que garantiu que lhe imprimissem suas feições. Por vezes, as preceptoras interferiam com algumas propostas e sugestões de modificação de detalhes. Ao fazerem seus relatos de experiência, esses oito alunos construíram a apresentação na qual cada um teve a palavra para comentar o processo vivido e as principais discussões que havíamos tido sobre os ACS. Sobre isso, um aluno comenta: “(...) no decorrer do trabalho, começamos a nos relacionar melhor com o nosso desafio de aprender e apresentar os ACS aos outros" (Nicholas).

A apresentação foi um momento especial. Entre outros grupos, mostramos nosso vídeo e os alunos foram ao palco contar um pouco do que aprendemos.

Com a afobação do vídeo, esquecemos que ele só tinha aproximadamente 15 minutos e o tempo da nossa apresentação era de 50 minutos. O que fazer nesses longos 35 minutos? Esse era nosso último problema. Resolvemos ser bem naturais, contar como foi a experiência de fazer um vídeo e fazer um resumo básico sobre o que era ACS e onde surgiram os agentes comunitários. Acabou que esses 'longos' 35 minutos foram curtos para partilharmos todas as experiências que nós adquirimos ao longo desses seis meses, com ajuda dos próprios agentes comunitários de saúde, diversos profissionais dessa área como a Márcia Valéria e a Ana Corbo e com as nossas preceptoras Marcia e Ialê (Mariana).

\section{E o que ficou...}

Muitos são os autores que inspiraram o trabalho das preceptoras ao longo deste Trabalho de Integração, mas Antonio Gramsci e Paulo Freire, por sua influência decisiva na proposição de novos métodos e abordagens de ensino-aprendizagem num sentido radicalmente transformador da realidade em que vivemos, merecem menção especial.

Gramsci foi um pensador marxista italiano combatente do fascismo e desenvolveu uma proposta de escola transformadora (que ele chamou unitária ou criadora), voltada ao desenvolvimento da autonomia intelectual dos alunos. Diz ele:

(...) a escola criadora não significa escola de 'inventores e descobridores'; indicase uma fase e um método de investigação e de conhecimento, e não um 'programa' predeterminado que obrigue à inovação e à originalidade a todo custo. 
Indica que a aprendizagem ocorre sobretudo graças a um esforço espontâneo e autônomo do discente, e no qual o professor exerce apenas uma função de guia amigável, como ocorre ou deveria ocorrer na universidade. Descobrir por si mesmo uma verdade, sem sugestões e ajudas exteriores, é criação, mesmo que a verdade seja velha, e demonstra a posse do método; indica que, de qualquer modo, entrou-se na fase da maturidade intelectual, na qual se podem descobrir verdades novas (2001, p. 40).

Paulo Freire foi um dos mais importantes teóricos brasileiros da educação. Passou a vida preocupado em desenvolver uma crítica à educação que chamava 'bancária', que restringia os alunos, em seus bancos escolares, ao papel de receptores de conteúdos passados pelos professores. Na visão bancária da educação, o saber é tido como uma doação dos que se julgam sábios aos que julgam nada saber.

Paulo Freire empenhou-se igualmente na construção de uma proposta revolucionária de educação, que se contrapusesse à educação bancária. Essa nova educação deve, de acordo com ele, articular-se a um projeto de sociedade diferente do que vivemos, assumindo papel importante na superação das relações de dominação e exploração. O ponto de partida desta educação libertadora é a reflexão sobre a realidade e a partir dela própria. Problematizando as relações dos homens entre si e com o mundo, educadores e educandos vão se (trans)formando e transformando o mundo em que vivem (Freire, 1970).

Nosso trabalho introdutório de pesquisa, por nos retirar a todos dos lugares de 'mestres sábios' e 'aprendizes ignorantes', nos deu a oportunidade de rompermos com o modelo bancário de educação, permitindo que todos aprendêssemos; e não apenas os conteúdos referentes ao nosso tema de pesquisa! Trabalhar em grupo envolveu aprender a ter opinião própria e a ouvir e respeitar as demais opiniões, disputar visões diferentes e chegar a um consenso, lidar com imprevistos, aceitar algumas limitações e transpor outras, enfim, nos obrigou a crescer enquanto pessoas, nos tornando todos mais sábios.

O contato com o cotidiano de um profissional que atua nas comunidades pobres e miseráveis, Brasil afora, por outro lado, nos obrigou a olhar a realidade - muitas vezes mais do que gostaríamos - de frente, e a nos posicionar diante dela. A situação precária de vida da grande maioria dos brasileiros não vai ser resolvida com o trabalho dos ACS, concluímos todos. Ao contrário, se não se revolucionar a sociedade que produz toda essa precariedade, nem um milhão de ACS vão dar conta do recado. Neste sentido, o trabalho desse profissional pode ser visto como um paliativo num contexto de aumento estrondoso da miséria no país decorrente da falta de emprego e aumento da exploração dos trabalhadores nesta virada para o século XXI. 
Contudo, quando escutamos Janete nos contar o sentido que ela atribui ao seu próprio trabalho, percebemos a necessidade de valorizar e respeitar os ACS como profissionais importantíssimos no desenvolvimento de uma estratégia de implementação do direito à saúde, condizente com os mais altos anseios dos defensores de um Sistema Único de Saúde (SUS) de qualidade para todos. E quando escutamos Tereza Ramos falar sobre a história e a atuação da Confederação Nacional dos Agentes Comunitários de Saúde, compreendemos que também é possível encarar os ACS como profissionais que têm um enorme potencial crítico de revolucionar suas condições precárias de formação e de trabalho e de se articularem na direção de uma nova sociedade, mais justa e igualitária.

Certamente, a maior parte do que aprendemos não é palpável e impossível de ser contada. Mesmo assim, as palavras inspiradas de uma aluna ajudam a nos fazer lembrar o quanto foi rico tudo que vivemos:

Hoje posso dizer que eu gostei muito de ter sido sorteada para falar sobre este tema, porque ele consegue mostrar a difícil realidade que enfrentamos todos os dias no Brasil. E o mais importante de tudo, os ACS nos fazem refletir em como existem diferenças sociais espalhadas em todo lugar, que fazem parte do nosso cotidiano, porém, já estamos tão acostumadas a vê-las, que muitas vezes nem nos abalamos com isso! (Thaciana).

\section{Notas}

1 Professora-pesquisadora da Escola Politécnica de Saúde Joaquim Venâncio, da Fundação Oswaldo Cruz (EPSJV/Fiocruz), Rio de Janeiro, Brasil. Mestre em Educação pela Universidade Federal Fluminense (UFF). <iale@fiocruz.br>

Correspondência: Fundação Oswaldo Cruz, Escola Politécnica de Saúde Joaquim Venâncio, Avenida Brasil, 4.365, Manguinhos, Rio de Janeiro, Brasil, CEP 21040-900.

2 Professora-pesquisadora da Escola Politécnica de Saúde Joaquim Venâncio, da Fundação Oswaldo Cruz (EPSJV/Fiocruz), Rio de Janeiro, Brasil. Doutora em Psicologia Social pela Universidade do Estado do Rio de Janeiro (Uerj). <mlopes@fiocruz.br>

3 Em 2007, os alunos ingressantes na EPSJV podiam estar inscritos no ensino médio integrado ao ensino técnico na própria escola (modalidade integrado); ou cursar o ensino 
médio em outra escola e o ensino técnico na EPSJV (modalidade concomitante); ou já ter concluído o ensino médio em outra escola e cursar apenas o ensino técnico na EPSJV (subseqüente). A partir de 2008, todos os alunos ingressantes nas habilitações técnicas oferecidas pela EPSJV deverão se matricular no Ensino Médio Integrado. As habilitações técnicas oferecidas em 2007 por esta escola foram: Gestão em Serviços de Saúde; Laboratório em Biodiagnóstico em Saúde; Registros em Informações em Saúde; Vigilância Sanitária e Saúde Ambiental.

4 Essas reflexões se expressam em tentativas de construção de modelos escolares alternativos, como é o caso da Escola da Ponte (Canário, 2004). Vários pensadores da educação desenvolvem análises sobre os processos escolares, dentre os quais destacamos Freire, Gramsci (2001), Esteban \& Zaccur (2002), Alves \& Garcia (1999).

5 Para maior aprofundamento sobre a temática, ver Escola Politécnica de Saúde Joaquim Venâncio (2007a e b).

${ }^{6}$ As preceptoras contaram com a colaboração dos professores Cláudio Gomes Ribeiro e José Roberto Franco Reis nesta preparação e no acompanhamento das atividades iniciais do grupo.

7 Pesquisadora da EPSJV e estudiosa do tema dos ACS, desenvolveu um trabalho de formação desses trabalhadores no Rio de Janeiro na comunidade do Turano, a partir de um programa sobre doenças sexualmente transmissíveis (DST/AIDS), bem como um curso de atualização em sistema de saúde para os ACS da Mangueira e um curso de educação em saúde para os da Vila do João. Coordenou a publicação da coleção "Educação Profissional e Docência em Saúde: a formação e o trabalho do Agente Comunitário de Saúde", material para docentes de cursos de formação de ACS.

8 Em 1994, 55 municípios colocaram em ação 328 equipes de Saúde da Família, sendo cada equipe composta por um médico, um enfermeiro, um auxiliar de enfermagem e quatro a seis agentes comunitários de saúde.

9 Assessora de comunicação da Secretaria Técnica da Rede de Escolas Técnicas do SUS (RET-SUS), à época, e coordenadora de comunicação, divulgação e eventos da EPSJV.

10 Na visita à Secretaria Técnica da RET-SUS, localizada na EPSJV, muitos alunos ali perceberam que esta é uma escola técnica do SUS, o que permitiu trabalhar um pouco o que é esse sistema.

11 Pesquisadora e coordenadora da Cooperação Internacional da EPSJV, estudou o tema dos ACS e trabalhou na regulamentação desta profissão pelo Centro de Promoção da Saúde. Foi também coordenadora do Programa de Saúde da Família e Agentes Comunitários de Saúde pela Secretaria Estadual de Saúde do Rio de Janeiro.

12 Um pouco do que Tereza Ramos abordou nesta aula inaugural pode ser lido na entrevista que concedeu à revista Trabalho, Educação e Saúde v. 5, n. 2.

13 Assistimos ao curta-metragem Ilha das Flores, de Jorge Furtado; a trechos de Babilônia 2000, de Eduardo Coutinho; e ao vídeo-documentário sobre o PSF na ilha de Paquetá, produzido pela Secretaria Estadual de Saúde do Rio de Janeiro, em parceria com a Escola de Cinema da UFF. 
14 Essas duas ACS atuam na região de Manguinhos e são vinculadas ao Centro de Saúde da Escola Nacional de Saúde Pública Sérgio Arouca, da Fundação Oswaldo Cruz.

\section{Referências}

ALVES, Nilda; GARCIA, Regina Leite. (Org.) O sentido da escola. Rio de Janeiro: DP\&A, 1999.

BENJAMIN, Walter. Experiência. In: Reflexões sobre a criança, o brinquedo e a educação. São Paulo: Duas Cidades; Editora 34, 2002, p. 21-25.

BRASIL. Decreto no 3.189, de 4 de outubro de 1999. Fixa diretrizes para o exercício da atividade de agente comunitário de saúde (ACS) e dá outras providências. Disponível em: <http://portal.saude.gov.br/portal/ arquivos/pdf/Decreton3.189.pdf $>$. Acesso em: 8 maio 2008.

BRASIL. Lei ${ }^{0} 11.350$, de 5 de outubro de 2006. Regulamenta o parágrafo $5^{\circ}$ do artigo 198 da Constituição, dispõe sobre o aproveitamento de pessoal amparado pelo parágrafo único do artigo $2^{\circ}$ da Emenda Constitucional $\mathrm{n}^{\circ} 51$, de 14 de fevereiro de 2006, e dá outras providências. Disponível em: $<$ http://www6.senado.gov.br/legislacao/ ListaPublicacoes.action? $\mathrm{id}=254831>$. Acesso em: 8 maio 2008.

BRASIL. Ministério da Saúde. Secretaria de Políticas de Saúde. Departamento de Atenção Básica. Modalidade de contratação de agentes comunitários de saúde: um pacto tripartite. Secretaria de Políticas de Saúde, Departamento de Atenção Básica. Brasília: Ministério da Saúde, 2002. Disponível em: $<$ http://bvsms.saude.gov.br/bvs/publicaco es/contratacao_agentes.pdf $>$. Acesso em: 8 maio 2008.
CANÁRIO, Rui; MATOS, Filomena; TRINDADE, Rui (Org.) Escola da Ponte: um outro caminho para a educação. São Paulo: Didática Suplegraf, 2004.

ESCOLA POLITÉCNICA DE SAÚDE JOAQUIM VENÂNCIO (Org.). Estudos de politecnia e saúde, v. 2. Rio de Janeiro: EPSJV, 2007a.

Debates e sintese do seminário Fundamentos da Educação Escolar do Brasil Contemporâneo. Rio de Janeiro: EPSJV, 2007b.

ESTEBAN, Maria Teresa; ZACCUR, Edwiges (Org.) Professora-pesquisadora: uma práxis em construção. Rio de Janeiro: DP\&A, 2002.

FREIRE, Paulo. Pedagogia do oprimido. Rio de Janeiro: Paz e Terra, 1970.

FONSECA, Angélica Ferreira; CORBO, Anamaria D'Andrea (Orgs.). O território e o processo saúde-doença. Coleção Educação Profissional e Docência em Saúde: a Formação e o Trabalho do Agente Comunitário de Saúde. Rio de Janeiro: EPSJV/Fiocruz, v. 1, 2007.

GRAMSCI, Antonio. Cadernos do cárcere: os intelectuais. O princípio educativo. Jornalismo, v. 2. Rio de Janeiro: Civilização Brasileira, 2001.

MARTINS, Carla Macedo; STAUFFER, Anakeila de Barros (Orgs.). Educação e saúde. Coleção Educação Profissional e 
Docência em Saúde: a Formação e o Trabalho do Agente Comunitário de Saúde. Rio de Janeiro: EPSJV/Fiocruz, v. 6, 2007.

MOROSINI, Márcia Valéria G. C. (Coord.). Coleção Educação Profissional e Docência em Saúde: a Formação e o Trabalho do Agente Comunitário de Saúde. Rio de Janeiro: EPSJV, v. 1 a v. 6, 2007.

MOROSINI, Márcia Valéria G. C.; REIS, José Roberto Franco (Orgs.). Sociedade, esta- do e direito à saúde. Coleção Educação Profissional e Docência em Saúde: a Formação e o Trabalho do Agente Comunitário de Saúde. Rio de Janeiro: EPSJV/Fiocruz, v. 2, 2007.

RAMOS, Tereza. Entrevista. Trabalho, Educação e Saúde, v. 5, n. 2, p. 329-337, 2007.

Recebido em 21/02/2008

Aprovado em 06/06/2008 